\title{
CONVERGENCE ANALYSIS OF ALGORITHMS FOR VARIATIONAL INEQUALITIES INVOLVING STRICTLY PSEUDO-CONTRACTIVE OPERATORS
}

\author{
Date of Receiving : $\quad 15.10 .2019$ \\ Date of Revision : $\quad 19.12 .2019$ \\ Date of Acceptance : 23.12 .2019
}

ASHISH NANDAL ${ }^{\dagger}$, RENU CHUGH, AND SUDESH KUMARI

\begin{abstract}
The purpose of the present work is to analyze the convergence of two new viscosity iterative algorithms for finding common solutions to variational inequality problem and fixed point problem of a finite system of strictly pseudocontractive operators in a $q$-uniformly smooth Banach space. Under suitable conditions, some strong convergence theorems are obtained. Using Matlab software, we numerically solve a convex feasibility problem. Our results improve some existing known results.
\end{abstract}

\section{Introduction}

Consider the well known convex feasibility problem (CFP):

$$
\text { finding an } x \in \bigcap_{i=1}^{k} C_{i}
$$

where $C_{1}, C_{2}, \ldots, C_{k}$ are intersecting closed convex subsets of a Banach space $X$. The $\mathrm{CFP}$ lies in center of many problems of mathematics and the physical sciences such as computerized tomography [14], radiation therapy treatment planning [7, 11, 15], sensor networking [3], image restoration [13]. A comprehensive study on algorithms for solving the CFP can be found in $[2,13]$.

Let $X^{*}$ be dual of a real Banach space $X$. For $q>1$, the generalized duality mapping $J_{q}: X \rightarrow 2^{X^{*}}$ is defined by

$$
J_{q}(u)=\left\{u^{*} \in X^{*}:\left\langle u, u^{*}\right\rangle=\|u\|^{q},\left\|u^{*}\right\|=\|u\|^{q-1}\right\}, \quad \forall u \in X,
$$

2010 Mathematics Subject Classification. 47H05, 47H10, 47J20, 47J25.

Key words and phrases. Iterative algorithm; convex feasibility problem; variational inequality; common fixed point; $q$-uniformly smooth Banach space.

Communicated by: Ramesh K. Vats

${ }^{\dagger}$ Corresponding author. 